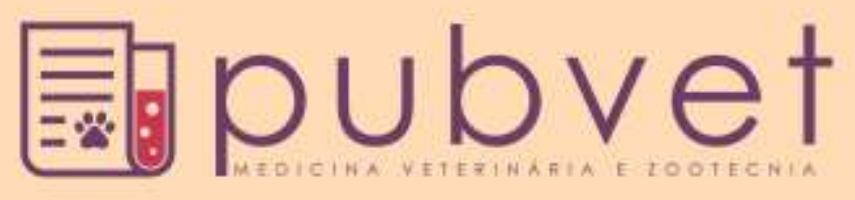

HTTP://DX.DOI.ORG/10.22256/PUBVET.V11N2.168-175

\title{
Isolamento bacteriano e suscetibilidade microbiana em amostras biológicas de cães
}

\author{
Claudio Douglas de Oliveira Guimarães ${ }^{1 *}$, Cleysiane da Silva Ferreira ${ }^{2}$, Kátia Maria \\ Costa da Silva ${ }^{3}$, Antonia Benedita Rodrigues Vieira ${ }^{4}$, José Maria dos Santos Vieira ${ }^{5}$ \\ 1*Médico veterinário, Mestre em Saúde e Produção Animal na Universidade Federal Rural da Amazônia (UFRA), discente do curso de \\ Especialização em Microbiologia Clínica, Universidade Federal do Pará - UFPA, Belém, Pará, Brasil cdoguimaraes@gmail.com \\ ${ }^{2}$ Biomédica, discente do curso de Especialização em Microbiologia Clínica/ICB/UFPA, Belém, Pará, Brasil enaisyelc@ gmail.com \\ ${ }^{3}$ Biomédica (UFPA), discente do curso de Especialização em Microbiologia Clínica/ICB/UFPA, Belém, Pará, Brasil \\ katcosta123@yahoo.com.br \\ ${ }^{4}$ Professora associada, coordenadora do Curso de Especialização em Microbiologia Clínica/ICB/UFPA, Belém, Pará, Brasil \\ arvieira@ufpa.br \\ ${ }^{5}$ Professor associado, docente do Curso de Especialização em Microbiologia Clínica/ICB/UFPA, Belém, Pará, Brasil jmvieira@ ufpa.br
}

\begin{abstract}
RESUMO. Infecções bacterianas são de grande importância na medicina veterinária e a escolha do antimicrobiano deve ser feita de forma criteriosa. Este estudo teve como objetivo identificar as bactérias e descrever o perfil de suscetibilidade bacteriana em amostras biológicas de cães encaminhadas para análise em um laboratório particular localizado em Belém, Pará, Brasil. Para isso, foram analisadas 59 amostras biológicas, sendo 34 amostras de secreção otológica e 25 amostras de urina, submetidos à cultura e antibiograma. Dados dos animais como sexo, idade e raça também foram considerados sendo, posteriormente, planificados e analisados no programa Microsoft Excel®. O principal agente bacteriano identificado em secreções otológicas foi Staphylococcus sp., enquanto que em amostras de urina Escherichia coli foi o mais frequente. Dentre os antimicrobianos testados a amicacina, ampicilina, ceftriaxona e imipenem obtiveram os melhores resultados de sensibilidade.
\end{abstract}

Palavras chave: Infecções bacterianas em cães, suscetibilidade antimicrobiana, antibióticos

\section{Bacterial isolation and microbial susceptibility in biological samples of dogs}

\begin{abstract}
Bacterial infections are of great importance in veterinary medicine and antimicrobial of choice must be made judiciously. This study aims to identify the bacteria and describe the bacterial susceptibility profile in biological samples of dogs sent for analysis in a particular laboratory in Belém, Pará, Brazil. For this, 59 biological samples were analyzed, 34 samples of ear secretion and 25 urine samples submitted for culture and sensitivity. Animal data such as sex, age and race were also considered and subsequently planned and analyzed in Microsoft Excel®. The main bacterial agent identified in ear secretions was Staphylococcus sp., while in urine samples Escherichia coli was the most frequent. None of the antimicrobial agents was able to inhibit the growth of the agents in this study; however, amikacin, ampicillin, ceftriaxone and imipenem obtained the best sensitivity results.
\end{abstract}

Keywords: Bacterial infections in dogs, antimicrobial susceptibility, antibiotics 


\title{
Aislamiento bacteriano y la susceptibilidad microbiana en muestras biológicas de perros
}

\begin{abstract}
RESUMEN. Las infecciones bacterianas son de gran importancia en la medicina veterinaria y la elección del antimicrobiano debe hacerse de forma criteriosa. Este estudio tuvo como objetivo identificar las bacterias y describir el perfil de susceptibilidad bacteriana en muestras biológicas de perros encaminadas para análisis en un laboratorio localizado en Belém, Pará, Brasil. Para ello, se analizaron 59 muestras biológicas, siendo 34 muestras de secreción otológica y 25 muestras de orina, sometidas a cultivo y antibiograma. Datos de los animales tales como el género, la edad y la raza también se consideraron, siendo posteriormente, proyectados y analizados con el programa Microsoft Excel®. El principal agente bacteriano identificado en las secreciones otológicas fue Staphylococcus sp., mientras que en las muestras de orina Escherichia coli fue la más frecuente. Entre los antimicrobianos probados amikacina, ampicilina, ceftriaxona e imipenen obtuvieron los mejores resultados de sensibilidad.
\end{abstract}

Palabras clave: Infecciones bacterianas en los perros, la susceptibilidad a los antimicrobianos, antibióticos

\section{Introdução}

Os antimicrobianos na medicina veterinária são usados de forma profilática, terapêutica e na produção animal (van den Bogaard and Stobberingh, 2000, Schwarz et al., 2001, Normanno et al., 2007, Guardabassi et al., 2009). Entre as enfermidades bacterianas que acometem os animais, a otite externa é uma das doenças mais comuns encontradas na prática veterinária, afetando cerca de 5 a $20 \%$ dos cães, sendo caracterizada como um processo inflamatório agudo ou crônico do epitélio do meato auditivo, na qual a etiologia é multifatorial (Oliveira et al., 2008, Penna et al., 2009, Almeida et al., 2016). Em menor escala, infecções do trato urinário (ITUs) também são responsáveis por grande parte dos atendimentos veterinários nesta espécie, resultantes principalmente de infecções ascendentes causadas por bactérias oportunistas, na maioria das vezes provenientes da microbiota intestinal (Low et al., 1988, Birchard and Sherding, 2008).

No entanto, o crescente e indiscriminado uso dessa classe de medicamentos é considerado uma das grandes causas da resistência bacteriana, fato que tem sido uma grande preocupação, tanto na medicina humana quanto na medicina veterinária, por se tratar de um problema complexo que envolve características bacterianas peculiares que favorecem o surgimento de bactérias resistentes (Blue and Wooley, 1977, Guardabassi et al., 2004, Moyaert et al., 2006, Umber and Bender, 2009).

Estudos recentes tem demonstrado que, animais de companhia como cães e gatos, podem ser fonte potencial de transmissão de resistência bacteriana intra e inter-espécies, inclusive envolvendo seres humanos (Guardabassi et al., 2004, Ungemach et al., 2006, Moyaert et al., 2006, Umber and Bender, 2009). Atualmente, sabe-se que gêneros de Staphylococcus coagulase positivos de animais apresentam considerável capacidade de transferir determinantes de resistência para cepas humanas e, por isso, as infecções por $S$. aureus multirresistentes em animais de companhia devem ser interpretadas como um problema de saúde pública (Junco and Barrasa, 2002, Springer et al., 2009). Sendo assim, o presente trabalho teve como objetivos identificar as bactérias e descrever o perfil de suscetibilidade bacteriana em amostras biológicas de cães.

\section{Material e Métodos}

Foram analisadas 59 amostras biológicas (secreção otológica e urina) de cães no setor de análise microbiológica de um laboratório particular de Belém, Pará, provenientes de várias clínicas localizadas na região metropolitana da capital no período de janeiro a agosto de 2015.

Como critério de seleção do material biológico, as amostras de secreção otológica foram analisadas apenas quando coletadas em swabs estéreis (meio Stuart) e as de urina, quando coletada por cistocentese e armazenada em recipiente estéril (tubo Falcon ou coletor universal). Para evitar sobreposição de dados e comprometimento das análises, foi considerada apenas um tipo de amostra para cada animal, sendo analisadas à medida que chegavam no laboratório. 
Para isolamento dos agentes bacterianos, as amostras foram semeadas em meios específicos, tais como Ágar MacConkey, Ágar Cromogênico e Ágar Sangue e incubados a $36^{\circ} \mathrm{C}$ por 24 horas. Após a incubação e crescimento microbiano, foram observados o tamanho, a cor e a morfologia das colônias que obtiveram crescimento positivo. As bactérias Gram negativas isoladas foram identificadas em meios diferenciais, como ágar TSI (Tríplice Açúcar Ferro), caldo Vermelho de Metila, caldo Voges-Proskauer, Ágar Citrato de Simmons, Ágar Motilidade Teste, Ágar Fenilalanina, Ágar Lisina, caldo Indol e caldo Nitrato. Já as bactérias Gram positivas foram submetidas às provas da catalase e da coagulase.

Para determinação da suscetibilidade aos antimicrobianos foi utilizado o método de difusão em Ágar Muller-Hinton segundo os critérios recomendados pelo Clinical and Laboratory Standards Institute (CLSI, 2009).

Os isolados bacterianos foram previamente identificados e em seguida transferidos para tubo contendo solução salina esterilizada $0,85 \%$ para verificação de turbidez segundo a escala de MacFarland. Posteriormente, cada suspensão bacteriana preparada foi semeada em ágar MullerHinton por meio de swab esterilizado. Em seguida foram colocados os discos de antibióticos selecionados anteriormente. Após incubação das placas a $35^{\circ} \mathrm{C}$ por 18 horas foi realizada a leitura dos resultados medindo-se, em milímetros, o halo formado ao redor dos discos e interpretando o resultado de acordo com a tabela de padrões de sensibilidade ou resistência pré-estabelecido para cada antibiótico. Os antimicrobianos testados foram: aminoglicosídeos (gentamicina, amicacina), $\quad \beta$-lactâmicos $\quad$ (amoxicilina, ampicilina, imipenem), cefalosporinas (cefalotina, cefuroxina, ceftriaxona), cloranfenicol, fluorquinolonas (norfloxacino, ciprofloxacino, levofloxacino), lincosaminas (clindamicina), macrolídeos (azitromicina) e sulfonamida.

A fim de relacionar o perfil geral dos indivíduos com os dados patológicos e microbiológicos, foram considerados animais filhotes ( $0-1$ ano), jovens e adultos ( $2-6$ anos) e idosos ( $>7$ anos). Os dados foram planificados e analisados através de estatística descritiva simples no programa Microsoft Office Excel 2007.

\section{Resultados e Discussão}

Ao longo do período de estudo, foram analisadas 59 amostras biológicas de cães, das quais 34 (58\%) corresponderam à secreção otológica e 25 (42\%) a amostras de urina, provavelmente a partir de suspeitas diagnósticas de otite e infecção do trato urinário (ITU), respectivamente. Esses resultados corroboram com outros estudos de cunho microbiológico (Tunon et al., 2008, Freitas et al., 2011, Ishii et al., 2011, Martins et al., 2011, Ferreira et al., 2014, Almeida et al., 2016) quanto ao tipo de material analisado, em que grande parte das amostras encaminhadas para análise consistiu de swabs contendo secreção otológica e frascos contendo urina coletada por cistoscentese.

No presente estudo, foi observada predominância de amostras biológicas provenientes de animais machos $(\mathrm{n}=33 ; 56 \%) \mathrm{em}$ relação às fêmeas $(\mathrm{n}=26 ; 44 \%)$, tanto para secreções otológicas quanto para urina. Santos (2007) relatou predominância de otites bacterianas em machos com idade igual ou superior a quatro anos, isto é, em animais adultos. No entanto, alguns autores sugerem que a predisposição a infecções do pavilhão auricular em cães está mais relacionada à conformação e apresentação da orelha nessa espécie nas diferentes raças do que com o sexo (Scott et al., 1996, Gotthelf, 2007). Em contrapartida, ITUs acometem predominantemente fêmeas caninas (Birchard and Sherding, 2008, Ferreira et al., 2014), diferente do encontrado no presente estudo. No entanto, devido ao baixo número de amostras utilizado, nossos resultados podem comprometer a comparação entre os sexos.

Em relação à idade dos animais dos quais as amostras foram coletadas, observou-se que a idade média foi sete anos, com variação de um a 15 anos e maior concentração de indivíduos idosos (acima de sete anos) (Figura 1). Observou-se, ainda, que filhotes, jovens e adultos (até seis anos) foram mais acometidos por otites bacterianas, enquanto que animais idosos (acima de sete anos) foram predominantemente acometidos por ITUs. Esses resultados corroboram com outros estudos (Thompson et al., 2011, Ferreira et al., 2014) e retifica um padrão observado no perfil microbiológico de otites e ITUs na espécie canina.

Quando considerado o tipo de amostra por raça, foi possível constatar que cães SRDs contribuíram com o maior número de material biológico, tanto otológico quanto urina $(\mathrm{n}=16$; $28 \%$ ) (Figura 2). Este resultado pode estar relacionado ao fato de cães SRDs representarem a maior parcela da população canina e, 
consequentemente, responderem por alta frequência dos atendimentos veterinários (Griffin, 1996).

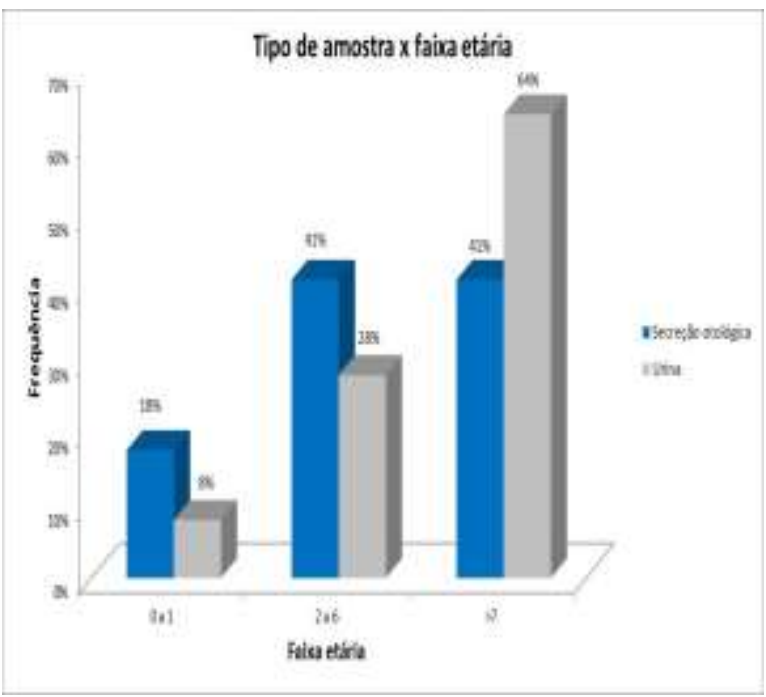

Figura 1. Distribuição percentual do tipo de amostra analisado de acordo com a faixa etária do animal.
Ainda quanto à distribuição racial, cães da raça Poodle contribuíram com o segundo maior quantitativo de swabs contendo secreção otológica, enquanto que cães da raça Schnauzer contribuíram com maior número de amostras de urina. A partir desses resultados, pode-se inferir que, diferente do que acontece com cães SRDs, os quais apresentaram sua elevada frequência de eventos amostrais devido ao número de atendimentos veterinários, otite em Poodles e ITUs em Schnauzeres podem estar mais relacionados à características raciais. De acordo com Santos (2007), Poodles apresentam hipertricose auricular no conduto auditivo vertical da orelha o que permite o acúmulo de secreção e umidade, fatores que propiciam ambiente favorável para a proliferação microbiana. Já em cães da raça Schnauzer, a frequência de ITUs está relacionada à disfunções hepáticas que favorecem o desenvolvimento de urolitíases e sua associação com infecção bacteriana, tal como observado por Forrester and Lees (1998).

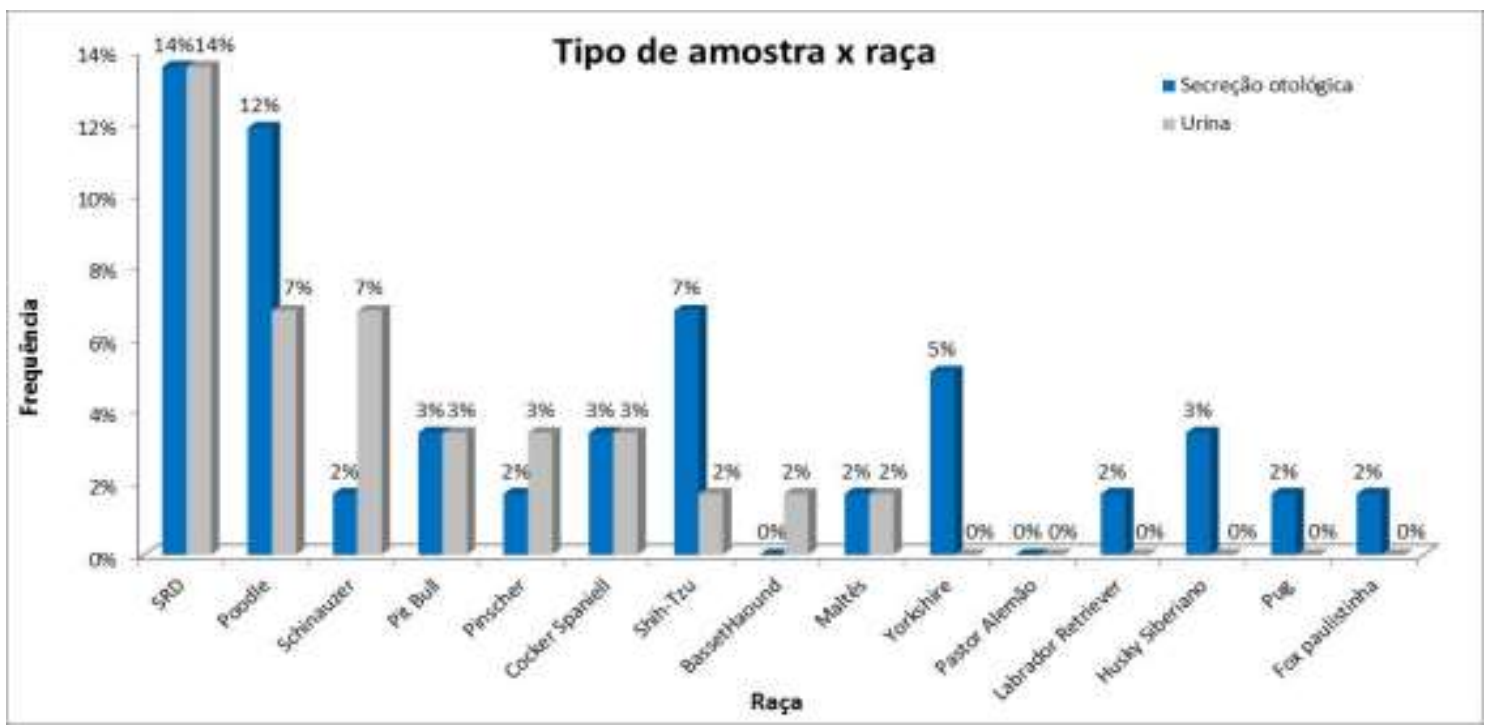

Figura 2. Distribuição percentual do tipo de amostra de acordo com a raça.

Assim como em muitos estudos de isolados microbiológicos em cães, observou-se, maior frequência de infecções causadas por bactérias Gram positivas $(\mathrm{n}=37 ; 63 \%)$ em relação às Gram negativas $(\mathrm{n}=22 ; 37 \%)$. Isso se deve, especialmente, ao tipo de amostra analisada, pois assim como identificado por Tunon et al. (2008), Ishii et al. (2011), Martins et al. (2011), as bactérias Gram positivas estão entre as mais frequentes causadoras de otites e isoladas em culturas provenientes de secreção otológica de cães, principal tipo de amostra analisada neste estudo. Entre as bactérias Gram positivas encontradas figuram Staphylococcus sp. $(\mathrm{n}=23$; $39 \%)$, Staphylococcus aureus $(\mathrm{n}=6 ; 10,1 \%)$, Enterococcus sp. $(\mathrm{n}=4 ; 6,8 \%)$ e Streptococcus $\mathrm{sp}$. ( $\mathrm{n}=4 ; 6,8 \%)$. Já entre as bactérias Gram negativas, colônias de Escherichia coli $(\mathrm{n}=18$; $30,5 \%)$ e Proteus mirabilis $(\mathrm{n}=4 ; 6,8 \%)$ foram isoladas, corroborando com dados disponíveis na literatura (Tunon et al., 2008, Martins et al., 2011, Ishii et al., 2011).

Quando analisados os agentes em cada tipo de amostra, verificou-se que Staphylococcus sp. foi isolado em mais da metade das amostras de 
secreção otológica (Tabela 1). Como observado por Martins et al. (2011) e Tunon et al. (2008) este agente figura como principal microrganismo envolvido em otites caninas independente da raça, sexo e região considerada. Já de acordo com Ishii et al. (2011), o mesmo agente foi isolado em diferentes tipos de amostras biológicas, participando, portanto, de processos infecciosos em diferentes sítios orgânicos, o que ilustra sua importância na medicina veterinária. Vale ressaltar que Staphylococcus sp faz parte da microbiota normal do conduto auditivo externo canino, podendo se multiplicar em animais otopatas por fatores de co-infecção ou baixa imunidade August (1993). Sendo assim, não se descarta a possibilidade de doenças primárias nesses animais.

Tabela 1. Distribuição do agente bacteriano isolado de cães de acordo com o sexo e o tipo de amostra biológica

\begin{tabular}{|c|c|c|c|c|c|c|c|c|}
\hline SX & A & $\begin{array}{c}\text { Staphylococcus } \\
\text { sp. }\end{array}$ & $\begin{array}{c}\text { Escherichia } \\
\text { coli } \\
\end{array}$ & $\begin{array}{c}\text { Staphylococcus } \\
\text { aureus }\end{array}$ & $\begin{array}{c}\text { Enterococcus } \\
\text { sp. }\end{array}$ & $\begin{array}{c}\text { Proteus } \\
\text { mirabilis } \\
\end{array}$ & $\begin{array}{c}\text { Streptococcus } \\
\text { sp. }\end{array}$ & $\mathrm{T}$ \\
\hline \multirow{2}{*}{ 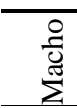 } & $\mathrm{SO}$ & 9 & 6 & 2 & 1 & 1 & 1 & 20 \\
\hline & $\mathrm{U}$ & 3 & 5 & 2 & 1 & 1 & 1 & 13 \\
\hline \multirow{3}{*}{ 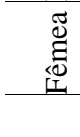 } & $\mathrm{SO}$ & 9 & 2 & 1 & 0 & 1 & 1 & 14 \\
\hline & $\mathrm{U}$ & 2 & 5 & 1 & 2 & 1 & 1 & 12 \\
\hline & $\mathrm{T}$ & 23 & 18 & 6 & 4 & 4 & 4 & 59 \\
\hline
\end{tabular}

Quanto às amostras de urina, o principal microrganismo encontrado foi Escherichia coli, agente etiológico mais frequente nas ITUs (Correia et al., 2007, Ferreira et al., 2014, Birchard and Sherding, 2008), as ITUs devem-se principalmente à infecções ascendentes causadas por bactérias oportunistas presentes em conteúdo fecal, levando à contaminação de sítios como vulva, vestíbulo ou prepúcio, alterando a microbiota normal, resultando em quadros de processos infecciosos. Além disso, de acordo com Clermont et al. (2000), E. coli é o agente com maior capacidade de causar infecções urinárias em função da existência de fatores de virulência bacteriana, que favorecem a colonização do trato urinário, principalmente por cepas pertencentes aos grupos filogenéticos B2 e D. Todos esses fatores justificam a alta frequência deste agente em uroculturas.

$\mathrm{Na}$ abordagem clínica, o tratamento de otite inclui limpeza e administração de antibióticos tópicos e sistêmicos (Malayeri et al., 2010). No entanto, mesmo com os avanços nas abordagens terapêuticas, a otite canina torna-se, muitas vezes, refratária ao tratamento. Isso em grande parte se deve à utilização exagerada de antimicrobianos, prática frequentemente empregada por veterinários de pequenos animais, sem uso de cultura microbiológica ou testes de sensibilidade aos antibióticos (Barrasa et al., 2000, Blue and Wooley, 1977). Diferente do que ocorre em cães otopatas, cães com ITU necessitam de tratamento antes da obtenção dos resultados definitivos dos testes de cultura e antibiograma. Sendo assim, Carvalhal et al. (2006) defendem que a escolha do antimicrobiano a ser utilizado inicialmente deve ser empírica, devendo corresponder aos achados clínicos, mas não exclui a necessidade dos exames de cultura e sensibilidade. No presente estudo, dos seis agentes microbianos isolados, o Staphylococcus sp. apresentou resistência à quase todos os antibióticos testados (93\%), exceto para ceftriaxona. Martins et al. (2011) já havia relatado alta sensibilidade de cepas de Staphylococcus sp à cefalexina, outro agente antimicrobiano pertencente à classe das cefalosporinas, tal como a ceftriaxona. Já Escherichia coli, principal agente isolado em amostras de urina, apresentou sensibilidade elevada para amicacina, ceftriaxona e imipenem (Tabela 2).

De um modo geral, nenhum dos antibióticos testados obteve eficácia para todos os isolados microbianos, isto é, foi capaz de inibir o crescimento de todos os micro-organismos. No entanto, amicacina, ampicilina, ceftriaxona e imipenem foram os que obtiveram melhores resultados por apresentarem $100 \%$ de sensibilidade para, pelo menos, três agentes microbianos. Em contrapartida, a azitromicina obteve os piores resultados de sensibilidade, não inibindo o crescimento de cinco dos seis microrganismos isolados. Estes resultados são preocupantes, uma vez que se observa resistência bacteriana para a maioria dos antibióticos testados. Este fato é corroborado por muitos estudos de cunho microbiológico, muitas vezes 
como consequência do uso indiscriminado de antibióticos pelos proprietários e pelo uso empírico dessas medicações (Blue and Wooley, 1977). Em todo caso, nossos resultados fortalecem a preocupação atual do surgimento de bactérias multirresistentes que podem inclusive passar do animal para o homem (potencial zooantropozoonótico) (Jones et al., 2007) o que eleva a importância desse tipo de estudo para a saúde dos animais e do homem.

Tabela 2. Distribuição dos agentes microbianos isolados de acordo com a sensibilidade aos antimicrobianos testados

\begin{tabular}{|c|c|c|c|c|c|c|c|c|c|c|c|c|c|c|}
\hline \multirow[t]{2}{*}{ ANT } & \multirow[t]{2}{*}{$\mathrm{P}$} & \multicolumn{2}{|c|}{$\begin{array}{l}\text { Staphylococcus } \\
\text { sp. }\end{array}$} & \multicolumn{2}{|c|}{$\begin{array}{l}\text { Escherichia } \\
\text { coli }\end{array}$} & \multicolumn{2}{|c|}{$\begin{array}{l}\text { Staphylococcus } \\
\text { aureus }\end{array}$} & \multicolumn{2}{|c|}{$\begin{array}{l}\text { Enterococcus } \\
\text { sp. }\end{array}$} & \multicolumn{2}{|c|}{$\begin{array}{l}\text { Proteus } \\
\text { mirabilis }\end{array}$} & \multicolumn{2}{|c|}{$\begin{array}{l}\text { Streptococcus } \\
\text { sp. }\end{array}$} & \multirow[t]{2}{*}{ Total } \\
\hline & & VA & $\%$ & VA & $\%$ & VA & $\%$ & VA & $\%$ & VA & $\%$ & VA & $\%$ & \\
\hline \multirow{2}{*}{ AMK } & $\mathrm{R}$ & 2 & 25 & 0 & 0 & 0 & 0 & 0 & 0 & 0 & 0 & 0 & 0 & 2 \\
\hline & $S$ & 6 & 75 & 5 & 100 & 3 & 100 & 0 & 0 & 1 & 100 & 0 & 0 & 15 \\
\hline \multirow{2}{*}{ AMX } & $\mathrm{R}$ & 2 & 25 & 4 & 40 & 0 & 0 & 1 & 25 & 0 & 0 & 1 & 50 & 8 \\
\hline & $S$ & 6 & 75 & 6 & 60 & 2 & 100 & 3 & 75 & 2 & 100 & 1 & 50 & 20 \\
\hline \multirow{2}{*}{ AMP } & $\mathrm{R}$ & 3 & 50 & 3 & 60 & 0 & 0 & 0 & 0 & 0 & 0 & 0 & 0 & 6 \\
\hline & S & 3 & 50 & 2 & 40 & 1 & 100 & 0 & 0 & 1 & 100 & 3 & 100 & 10 \\
\hline \multirow{2}{*}{ AZT } & $\mathrm{R}$ & 8 & 89 & 4 & 80 & 2 & 100 & 3 & 100 & 1 & 100 & 1 & 100 & 19 \\
\hline & S & 1 & 11 & 1 & 20 & 0 & 0 & 0 & 0 & 0 & 0 & 0 & 0 & 2 \\
\hline \multirow{2}{*}{ CEF } & $\mathrm{R}$ & 0 & 0 & 0 & 0 & 1 & 100 & 1 & 33 & 0 & 0 & 1 & 100 & 3 \\
\hline & $\mathrm{S}$ & 6 & 100 & 5 & 100 & 0 & 0 & 2 & 67 & 2 & 100 & 0 & 0 & 15 \\
\hline \multirow{2}{*}{ CFT } & $\mathrm{R}$ & 4 & 50 & 2 & 100 & 2 & 50 & 0 & 0 & 0 & 0 & 0 & 0 & 8 \\
\hline & S & 4 & 50 & 0 & 0 & 2 & 50 & 0 & 0 & 1 & 100 & 0 & 0 & 7 \\
\hline \multirow{2}{*}{$\mathrm{CFU}$} & $\mathrm{R}$ & 6 & 50 & 2 & 33 & 4 & 80 & 0 & 0 & 0 & 0 & 3 & 100 & 15 \\
\hline & S & 6 & 50 & 4 & 67 & 1 & 20 & 0 & 0 & 0 & 0 & 0 & 0 & 11 \\
\hline \multirow{2}{*}{$\mathrm{CPR}$} & $\mathrm{R}$ & 2 & 9 & 7 & 41 & 0 & 0 & 1 & 33 & 0 & 0 & 1 & 25 & 11 \\
\hline & $\mathrm{S}$ & 20 & 91 & 10 & 59 & 5 & 100 & 2 & 67 & 4 & 100 & 3 & 75 & 44 \\
\hline \multirow{2}{*}{ CLI } & $\mathrm{R}$ & 5 & 42 & 7 & 100 & 3 & 75 & 0 & 0 & 0 & 0 & 3 & 100 & 18 \\
\hline & S & 7 & 58 & 0 & 0 & 1 & 25 & 0 & 0 & 0 & 0 & 0 & 0 & 8 \\
\hline \multirow{2}{*}{ CLN } & $\mathrm{R}$ & 5 & 36 & 4 & 44 & 2 & 50 & 0 & 0 & 0 & 0 & 1 & 33 & 12 \\
\hline & $S$ & 9 & 64 & 5 & 56 & 2 & 50 & 0 & 0 & 2 & 100 & 2 & 67 & 20 \\
\hline \multirow{2}{*}{ GET } & $\mathrm{R}$ & 7 & 39 & 7 & 47 & 0 & 0 & 3 & 100 & 0 & 0 & 2 & 67 & 19 \\
\hline & S & 11 & 61 & 8 & 53 & 2 & 100 & 0 & 0 & 2 & 100 & 1 & 33 & 24 \\
\hline \multirow{2}{*}{ IPM } & $\mathrm{R}$ & 1 & 11 & 0 & 0 & 1 & 50 & 0 & 0 & 0 & 0 & 0 & 0 & 2 \\
\hline & $S$ & 8 & 89 & 3 & 100 & 1 & 50 & 0 & 0 & 1 & 100 & 3 & 100 & 16 \\
\hline \multirow{2}{*}{ LVX } & $\mathrm{R}$ & 1 & 7 & 6 & 46 & 1 & 17 & 1 & 50 & 0 & 0 & 0 & 0 & 9 \\
\hline & $S$ & 14 & 93 & 7 & 54 & 5 & 83 & 1 & 50 & 4 & 100 & 3 & 100 & 34 \\
\hline \multirow{2}{*}{ NFX } & $\mathrm{R}$ & 4 & 50 & 3 & 50 & 3 & 75 & 0 & 0 & 0 & 0 & 0 & 0 & 10 \\
\hline & $\mathrm{S}$ & 4 & 50 & 3 & 50 & 1 & 25 & 0 & 0 & 1 & 100 & 0 & 0 & 9 \\
\hline \multirow{2}{*}{ PEC } & $\mathrm{R}$ & 7 & 54 & 10 & 91 & 3 & 60 & 2 & 67 & 0 & 0 & 1 & 33 & 23 \\
\hline & $S$ & 6 & 46 & 1 & 9 & 2 & 40 & 1 & 33 & 1 & 100 & 2 & 67 & 13 \\
\hline \multirow{2}{*}{ SFD } & $\mathrm{R}$ & 10 & 56 & 9 & 82 & 5 & 100 & 1 & 50 & 1 & 33 & 4 & 100 & 30 \\
\hline & $\mathrm{S}$ & 8 & 44 & 2 & 18 & 0 & 0 & 1 & 50 & 2 & 67 & 0 & 0 & 13 \\
\hline
\end{tabular}

$\mathrm{ANT}=$ antimicrobiano; $\mathrm{P}=$ parâmetro; $\mathrm{R}=$ resistência; $\mathrm{S}=$ sensibilidade, $\mathrm{VA}=$ valor absoluto. $\mathrm{AMK}=\mathrm{amicacina} ; \mathrm{AMX}=$ amoxilina; $\mathrm{AMP}=$ ampicilina; $\mathrm{AZT}=$ azitromicina; $\mathrm{CEF}=$ ceftriaxona; $\mathrm{CFT}=$ cefalotina; $\mathrm{CFU}=$ cefuroxina; $\mathrm{CPR}=$ ciprofloxacino; $\mathrm{CLI}=$ clindamicina; $\mathrm{CLN}=$ cloranfenicol; GNT= gentamicina; $I P M=$ imipenem; $L V X=$ levofloxacin; $N F X=$ norfloxacin; $P E C=$ penicilina e $S F D=$ sulfonamida.

\section{Conclusão}

No presente estudo, foi possível identificar que Staphylococcus sp. e Escherichia coli foram os principais agentes isolados em secreção otológica e amostras de urina, respectivamente, o que ilustra a importância desses micro-organismos em processos infecciosos na espécie canina. Amicacina, ampicilina, ceftriaxona e imipenem obtiveram os melhores resultados de sensibilidade, dentre os antibióticos testados.

Vale ressaltar que, devido à falta de padronização de antibióticos utilizados em 
estudos de suscetibilidade bacteriana, análises comparativas tornam-se pouco eficazes. No entanto, é fato que este estudo trás novas informações quanto ao perfil de sensibilidade e resistência bacteriana em cães e retifica a importância da realização do exame de suscetibilidade bacteriana na rotina clínica veterinária como forma de direcionar o tratamento de infecções bacterianas e de prevenir a transmissão de fatores de resistência. Sugere-se maior investimento financeiro e metodológico em estudos que considerem possíveis co-infecções com outros microorganismos a fim de relacionar a verdadeira importância clínica das bactérias e demais patógenos envolvidos em processos infecciosos em animais domésticos assim como fatores de resistência associados aos agentes microbianos.

\section{Referências bibliográficas}

Almeida, M. S., Santos, S. B., Mota, A. R., Silva, L. T., Silva, L. B. \& Mota, R. A. 2016. Isolamento microbiológico do canal auditivo de cães saudáveis e com otite externa na região metropolitana de Recife, Pernambuco. Pesquisa Veterinária Brasileira, 36, 29-32.

August, J. R. 1993. Enfermedades del oído. Las Clínicas Vetrinárias de Norteamerica, 18, 1274.

Barrasa, J. L. M., Lupiola Gomez, P., Gonzalez Lama, Z. \& Tejedor Junco, M. T. 2000. Antibacterial susceptibility patterns of Pseudomonas strains isolated from chronic canine otitis externa. Journal of Veterinary Medicine, Series B, 47, 191-196.

Birchard, S. J. \& Sherding, R. G. 2008. Manual Saunders: clínica de pequenos animais, São Paulo.

Blue, J. L. \& Wooley, R. E. 1977. Antibacterial sensitivity patterns of bacteria isolated from dogs with otitis externa. Journal of the American Veterinary Medical Association, 171, 362-363.

Carvalhal, G. F., Rocha, L. C. A. \& Monti, P. R. 2006. Urocultura e exame comum de urina: considerações sobre sua coleta e interpretação. Revista da AMRIGS, 50, 59-62.

Clermont, O., Bonacorsi, S. \& Bingen, E. 2000. Rapid and simple determination of the Escherichia coli phylogenetic group. Applied and Environmental Microbiology, 66, 45554558.
CLSI. 2009. Performance Standards for Antimicrobial Disk Susceptibility Tests: Approved Standards. National Committee for Clinical Laboratory Standards.

Correia, C. M., Costa, E., Peres, A. M., Alves, M., Pombo, G. \& Estevinho, L. M. 2007. Etiologia das infecções do tracto urinário e sua susceptibilidade aos antimicrobianos. Acta Medical Portuguesa.

Ferreira, M. C., Nobre, D., Oliveira, M. G. X., Oliveira, M. C. V., Cunha, M. P. V., Menão, M. C., Dellova, D. C. A. \& Knöbl, T. 2014. Agentes bacterianos isolados de cães e gatos com infecção urinária: perfil de sensibilidade aos antimicrobianos. Atas de Saúde Ambiental, 2, 29-37.

Forrester, S. D. \& Lees, G. E. 1998. Nefropatias e ureteropatias. In: Birchard, S. J. \& Sherding, R. G. (eds.) Manual Saunders Clínica de Pequenos Animais. Roca, São Paulo.

Freitas, L. R., Silva, A. C. R., Stela, A. E. \& Portilho, E. F. 2011. Causative agents of urinary infections in dogs in Rio Verde-GO: occurrence and determination of antimicrobial sensitivity. PUBVET, 5, 1166.

Gotthelf, L. N. 2007. Doenças do ouvido em pequenos animais. Editora Roca, São Paulo.

Griffin, C. E. 1996. Malassezia paronychia in atopic dogs. Proceedings of The 12th Annual $A A V D$ and ACVD Members' Meeting. Las Vegas.

Guardabassi, L., Jensen, L. B. \& Kruse, H. 2009. Guia de antimicrobianos em veterinária. Artmed Editora, Porto Alegre.

Guardabassi, L., Schwarz, S. \& Lloyd, D. H. 2004. Pet animals as reservoirs of antimicrobialresistant bacteria: Review. Journal of Antimicrobial Chemotherapy, 54, 321-332.

Ishii, J. B., Freitas, J. C. \& Arias, M. V. B. 2011. Resistência de bactérias isoladas de cães e gatos no Hospital Veterinário da Universidade Estadual de Londrina (2008-2009). Pesquisa Veterinária Brasileira, 31, 533-537.

Jones, R. D., Kania, S. A., Rohrbach, B. W., Frank, L. A. \& Bemis, D. A. 2007. Prevalence of oxacillin-and multidrug-resistant staphylococci in clinical samples from dogs: 1,772 samples (2001-2005). Journal of the American Veterinary Medical Association, 230, 221-227.

Junco, M. T. \& Barrasa, J. L. 2002. Identification and antimicrobial susceptibility of coagulase 
positive staphylococci isolated from healthy dogs and dogs suffering from otitis externa. Journal of Veterinary Medicine, Series B, 49, 419-423.

Low, D. A., Braaten, B. A., Ling, G. V., Johnson, D. L. \& Ruby, A. L. 1988. Isolation and comparison of Escherichia coli strains from canine and human patients with urinary tract infections. Infection and Immunity, 56, 26012609.

Malayeri, H. Z., Jamshidi, S. \& Salehi, T. Z. 2010. Identification and antimicrobial susceptibility patterns of bacteria causing otitis externa in dogs. Veterinary Research Communications, 34, 435-444.

Martins, E. A., Momesso, C. S., Nardo, C. D. D., Castro, K. F., Atique, T. S. C., Netto, H. A. \& Furini, A. A. C. 2011. Estudo clínico e microbiológico de otite externa de cães atendidos em hospital veterinário do noroeste paulista. Acta Veterinaria Brasilica, 5, 61-67.

Moyaert, H., De Graef, E., Haesebrouck, F. \& Decostere, A. 2006. Acquired antimicrobial resistance in the intestinal microbiota of diverse cat populations. Research in Veterinary Science, 81, 1-7.

Normanno, G., Corrente, M., La Salandra, G., Dambrosio, A., Quaglia, N. C., Parisi, A., Greco, G., Bellacicco, A. L., Virgilio, S. \& Celano, G. V. 2007. Methicillin-resistant Staphylococcus aureus (MRSA) in foods of animal origin product in Italy. International journal of food microbiology, 117, 219-222.

Oliveira, L. C., Carvalho, C., Leite, C. A. L. \& Brilhante, R. S. N. 2008. Comparative study of the microbial profile from bilateral canine otitis externa. Canadian Veterinary Journal, 49, 785-788.

Penna, B., Varges, R., Medeiros, L., Martins, G. M., Martins, R. R. \& Lilenbaum, W. 2009. In vitro antimicrobial susceptibility of staphylococci isolated from canine pyoderma in Rio de Janeiro, Brazil. Brazilian Journal of Microbiology, 40, 490-494.

Santos, R. R. 2007. Sensibilidade in vitro da microbiota da orelha de cães com otite externa a cinco antimicrobianos. Acta Scientiae Veterinariae, 35, 433-435.
Schwarz, S., Kehrenberg, C. \& Walsh, T. R. 2001. Use of antimicrobial agents in veterinary medicine and food animal production. International Journal of Antimicrobial Agents, 17, 431-437.

Scott, D. W., Muller, G. H. \& Kirk, R. W. 1996. Dermatologia dos pequenos animais. Interlivros, Rio de Janeiro.

Springer, B., Orendi, U., Much, P., Höger, G., Ruppitsch, W., Krziwanek, K., Metz-Gercek, S. \& Mittermayer, H. 2009. Methicillinresistant Staphylococcus aureus: a new zoonotic agent? Wiener Klinische Wochenschrift, 121, 86-90.

Thompson, M. F., Litster, A. L., Platell, J. L. \& Trott, D. J. 2011. Canine bacterial urinary tract infections: new developments in old pathogens. The Veterinary Journal, 190, 2227.

Tunon, G. I. L., Silva, E. P. \& Faierstein, C. C. 2008. Isolamento de estafilococos multirresistentes de otites em cães e sua importância para a saúde pública. BEPA. Boletim Epidemiológico Paulista, 5, 4-7.

Umber, J. K. \& Bender, J. B. 2009. Pets and antimicrobial resistance. Veterinary Clinics of North America: Small Animal Practice, 39, 279-292.

Ungemach, F. R., Müller-Bahrdt, D. \& Abraham, G. 2006. Guidelines for prudent use of antimicrobials and their implications on antibiotic usage in veterinary medicine. International Journal of Medical Microbiology, 296, 33-38.

van den Bogaard, A. E. \& Stobberingh, E. E. 2000. Epidemiology of resistance to antibiotics: links between animals and humans. International Journal of Antimicrobial Agents, 14, 327-335.

\section{Article History:}

Received 8 November 2016

Accepted 6 December 2016

Available on line 30 January 2017

License information: This is an open-access article distributed under the terms of the Creative Commons Attribution License 4.0, which permits unrestricted use, distribution, and reproduction in any medium, provided the original work is properly cite 